\title{
A National Survey of Teachers' Promotion of Self-Determination and Student-Directed Learning
}

\author{
Michael L. Wehmeyer, The University of Kansas \\ Martin Agran, University of Northern Iowa \\ Carolyn Hughes, Vanderbilt University
}

\begin{abstract}
This article describes the findings of a national survey of teachers' opinions regarding the value of selfdetermination and issues relating to teaching skills leading to this outcome. Respondents were secondary-level educators serving students with varying types and severity of disabling conditions. Findings indicated that a majority of respondents believed that instruction in self-determination was important, but teachers differed in their responses regarding the strategies taught and the extent and type of instruction provided based on the severity of the student's disability. Implications for educational practice are discussed.
\end{abstract}

Promoting the self-determination of students with disabilities has become an essential component of many education an (transition programs (Field, Hoffman, \& Spezia, 1998; Field Martin, Miller, Ward, \& Wehmeyer, 1998b; Wehmeyer, Agran, \& Hughes, 1998). Halloran (1993) referred to selfdetermination as education's ultimate goal. Wehman (1993 identified enhanced student choice as one of the most critical transition issues for the 21 st century, and the Division of Career Development and Transition recently released a position statement emphasizing the importance of self-determination for youth with disabilities (Field, Martin, Miller, Ward, 8 Wehmeyer, 1998a). Szymanski (1994) suggested that to empower students through the transition process, intervention must be designed to be maximally under the control of the student rather than others and should be designed to facilitate individual independence and autonomy.

The importance of self-determination to transition ha been shown empirically as well. Wehmeyer and Schwart (1997) examined the impact of student self-determination status on the postsecondary outcomes of 80 youth with mild mental retardation or a learning disability. One year after these students left high school, they and their families were contacted to determine their status in several areas, including living arrangements, current and past employment situations postsecondary education status, and community integration outcomes. These data were then analyzed, controlling for level of intelligence and type of disability. The data suggested a consistent trend in which selfdetermined youth had more positive adult outcomes than their peers with lower self-determination scores. Students in the high self-determination group (e.g., top third of self-determination scores) were more likely to have expressed a preference to live outside the family home and were more independent (including maintaining a savings or checking account). Eighty percent of the high self-determination group worked for pay 1 year after graduation, although only $43 \%$ of the low self-determination group did likewise. Among school-leavers who were employed, youth in the high self-determination group earned significantly more per hour (mean $=\$ 4.26)$ than their peers in the low selfdetermination group $($ mean $=\$ 1.93)$.

Numerous curricular and assessment materials are now available for use by teachers to promote their students' selfdetermination (Field \& Hoffman, 1996; Field et al., 1998; Wehmeyer et al., 1998) and educational involvement (Halpern et al., 1997; Martin, Marshall, Maxson, \& Jerman, 1996; Van Reusen, Bos, Schumaker, \& Deshler, 1994; Wehmeyer \& Sands, 1998). We have been engaged in research to develop a theoretical model of self-determination to provide a foundation upon which to describe development, design intervention, and conduct research on this construct. Through this work we have proposed (Wehmeyer, 1998, 1999; Wehmeyer et al., 1998) a functional model in which self-determination is defined as "acting as the primary causal agent in one's life and making choices and decisions regarding one's quality of life free from undue external influence or interference" (Wehmeyer, 1996, p.

24). Self-determined behavior refers to actions that are 
identified by four essential characteristics based on the function (purpose) of the behavior: (1) The person acted autonomously; (2) the behavior(s) are self-regulated; (3) the person initiated and responded to event(s) in a psychologically empowered manner; and (4) the person acted in a self-realizing manner (Wehmeyer, Kelchner, \& Richards, 1996). People are self-determined based not on what they do, (e.g., get married, stay single) but based on the purpose or function of their action (to take control over their lives, live the way they want). Within this model, we have described the development of component elements of self-determined behavior in order to design instructional activities for students across their school career (Wehmeyer, 1997; Wehmeyer, Sands, Doll, \& Palmer, 1998). These component elements include, but are not limited to, choice and decision-making skills, problem-solving skills, goal setting and attainment skills, self-management skills, self-advocacy skills, positive perceptions of control and efficacy, and self-knowledge and self-awareness. A wide array of instructional methods, materials, and strategies can focus learning on each of these areas, with the result that young people become more autonomous, self-regulating, psychologically empowered and self-realizing and, thus, more self-determined (Wehmeyer et al., 1998).

One of the primary instructional activities that can promote student self-regulation of learning and, ultimately, promote self-determination is the use of student-directed learning strategies. Student-directed learning strategies, which include self-management strategies, involve teaching students to modify and regulate their own behavior (Agran, 1997). Research in education and vocational rehabilitation has shown that student-directed learning strategies are as successful as, and often more successful than, teacher-directed instructional strategies and that these strategies represent effective means to enhance learning. Such student-directed or self-regulation strategies have demonstrated educational efficacy across a wide age range of students with a variety of disabilities. Selfmonitoring and self-recording procedures have been shown to improve the motivation and performance of students with disabilities (Kapadia \& Fantuzzo, 1988; Malone \& Mastropieri, 1992; McCarl, Svobodny, \& Beare, 1991). For example, Trammel, Schloss, and Alper (1994) found that self-recording (graphing) and student-directed goal setting enabled students with learning disabilities to increase the number of assignments they completed successfully. Self-instructional strategies have also proven to be beneficial for individuals with disabilities. Self-instruction refers to verbalizations an individual emits to cue, direct, or maintain his or her own behavior (Hughes \& Agran, 1994). A number of studies have found that selfinstruction training is useful for increasing job-related (Agran, Fodor-Davis, \& Moore, 1986; Hughes, 1992; Hughes, Hugo, \& Blatt, 1996; Hughes \& Rusch, 1989; Rusch, McKee, ChadseyRusch, \& Renzaglia, 1988; Salend, Ellis, \& Reynolds, 1989) and social (Hughes, Harmer, Killian, \& Niarhos, 1995; Hughes, Killian, \& Fischer, 1996) skills of individuals with mental retardation. Self-instruction was found to improve essay composition skills of students with learning disabilities (Graham \& Harris, 1989).

A third self-directed learning strategy is self-evaluation or self-judgment. Schunk (1981) showed that students who verbalized cognitive strategies related to evaluating their study and work skills had increased math achievement scores. Brownell, Colletti, ErsnerHershfield, Hershfield, \& Wilson (1977) found that students who determined their performance standards demonstrated increased time on-task when compared with students operating under imposed standards.

A fourth component of self-regulated learning, selfreinforcement, also leads to increased performance. For example, Frea and Hughes (1997) used a combination of self-reinforcement and self-monitoring procedures to improve the social performance of students with mental retardation in a school setting. Martella, Leonard, Marchand-Martella, and Agran (1993) used a combination of self-monitoring, goal setting, and selfreinforcement to decrease the negative conversational statements of a student with mental retardation.

To date, there has been limited information about the degree to which teachers promote their students' self-determination and teach students self-directed learning. Agran, Snow, and Swaner (1999) conducted a statewide survey in Utah of teacher perceptions of the benefits of self-determination, the degree to which teachers taught their students strategies that promote selfdetermination, and the extent to which self-determination-related goals and objectives were included in Individualized Education Programs (IEPs). Teachers rated selfdetermination as an important curricular area, with $42 \%$ of respondents suggesting that self-determination was a "very important" area and 35\% ranking it as "important." Only 3\% of teachers rated it as a low priority. However, $55 \%$ of the respondents indicated that self-determination-related skills were either not included in the IEPs they developed or appeared only on some. Additionally, $59 \%$ of teachers indicated that discussing the need to be self-determined with their students was not at all or only moderately important. In all, Agran and colleagues found that teachers of students with disabilities felt self-determination was important but did not place considerable emphasis on this area in curricular and planning activities. This finding was supported by Wehmeyer and Schwartz (1998), who examined more than 800 transition goals from the IEPs of students with mental retardation receiving services in two states. Despite the need for students with mental retardation to learn a variety of skills important to selfdetermination (e.g., solving problems, making decisions, setting and tracking goals), not a single goal on these transition plans targeted instructional efforts to promote self-determination.

Hughes and colleagues (1997) conducted a statewide survey of high school transition teachers in Tennessee. Findings corroborated teachers' perceptions of the importance of selfdetermination and related skills, and teachers identified 172 strategies they used to promote self-determination. However, the extent to which teachers actually implemented these strategies is 
unknown. Given the current interest in promoting selfdetermination, it is ironic that little is known about how, or for that matter if, self-determination is being promoted.

This study reports findings from a national survey on self-determination and the use of student-directed learning strategies conducted of teachers serving adolescents with disabilities. The survey sought to provide further information about the use of student-directed learning strategies by students and to overcome limitations of previous research in this area, primarily related to the limited generalizability of findings because of restricted samples (e.g., one or two states) and limited sample sizes. We also examined whether classroom setting or type of disability served influenced teachers' promotion of self-determination and use of student-directed strategies.

\section{Method}

\section{Participants}

The target audience for the survey were teachers providing instruction to students with disabilities between the ages of 14 and 21 and, thus, eligible for transition-related services through the Individuals with Disabilities Education Act (IDEA). A survey, described subsequently, was mailed to 9,762 persons identified as educators from the membership lists of TASH (formerly The Association for Persons with Severe Handicaps) and several subdivisions of the Council for Exceptional Children, including the Mental Retardation and Developmental Disabilities division and the Division of Learning Disabilities. We specified that only those people who were currently responsible for designing and implementing the educational program of students with disabilities ages 14 and over return the survey. All respondents who returned a completed survey were entered into a drawing to receive a copy of a textbook on teaching selfdetermination to youth with disabilities. Fifty copies of the text were sent to randomly drawn respondents.

We received a total of 1,219 completed surveys. Respondents included teachers from all 50 states and two U.S. territories. Total number of responses from teachers in the various states and territories ranged from 2 respondents to 79 respondents, with the average number of respondents per state equal to 23 and the modal return equal to 24 . Twenty-one percent of respondents identified a middle school campus as their principle teaching assignment, $5 \%$ a junior high campus, $42 \%$ a senior high campus, $2 \%$ a postsecondary education campus, and $30 \%$ indicated they taught in other (residential facility, hospital) or multiple settings. The majority of the respondents $(n=1,159)$ indicated they were trained as a special educator. Respondents were asked to identify the primary disability of students they taught but could select multiple categories (see Table 1). Respondents were also asked to identify one educational environment in which students for whom they were responsible received their education (see Table 2).
These environments were taken directly from IDEA and were defined in the survey using IDEA definitions. The instructional environment most frequently reported was a separate class (41\%), followed by a regular class (26\%), and a resource room (16\%).

TABLE 1. Frequency of Respondents and Percentage of All Respondents Indicating Responsibility for Instructional Programming by Disability

\begin{tabular}{lcc}
\hline \multicolumn{1}{c}{ Disability } & Frequency & $\begin{array}{r}\% \text { of total } \\
\text { respondents } \\
(n=1,219)\end{array}$ \\
\hline Moderate mental retardation & 682 & 55 \\
Mild mental retardation & 604 & 50 \\
Specific learning disability & 529 & 44 \\
Multiple disabilities & 482 & 40 \\
Severemental retardation & 463 & 38 \\
Speechllanguageimpairment & 424 & 35 \\
Autism & 380 & 31 \\
Serious emotional disturbance & 322 & 26 \\
Orthopedic impairments & 262 & 21 \\
Visual impairments & 242 & 20 \\
Hearing impairments & 204 & 17 \\
Traumatic braininjury & 179 & 15 \\
Deaf-blindness & 91 & 8
\end{tabular}

Note. Respondents could select multiple categories.

TABLE 2. Primary Instructional Environment

\begin{tabular}{lcc}
\hline \multicolumn{1}{c}{ Environment } & Frequency & $\begin{array}{c}\% \text { of total } \\
\text { respondents } \\
(n=1,194)^{\mathrm{a}}\end{array}$ \\
\hline Regularclass $^{\mathrm{b}}$ & 306 & 26 \\
Resource room $^{\mathrm{c}}$ & 194 & 16 \\
Separate class $^{\mathrm{d}}$ & 488 & 41 \\
Separate school $^{\mathrm{e}}$ & 173 & 15 \\
Residential facility $^{\mathrm{f}}$ & 25 & $<2$ \\
Homeboundhospital $^{\mathrm{g}}$ & 8 & $<1$
\end{tabular}

Missing data or selected more than one category $(\mathrm{N}=25) .{ }^{\mathrm{b}}$ Regular class: Includes students who receive the majority of their education program in a regular classroom and receive special education and related services outside the regular classroom for less than $21 \%$ of the school day. Resource room: Includes students who receive special education and related services outside the regular classroom for at least $21 \%$ but nomorethan $60 \%$ of the school day. ${ }^{\mathrm{d}}$ Separate class: Includes students who receive special education and related services outside the regular classroom for more than $60 \%$ of the school day. 'Separate school: Includes students who receive education in privateandpublicsepaTte day schools for students with disabilities for more than $50 \%$ of theschoolday. ${ }^{\text {'Residential }}$ facility: Includes students who receive education in a public or private residential facility, at public expense, for more than $50 \%$ of the school day. ${ }^{g}$ Homebound/hospitalenvironment: Includes students placed in and receiving special education in hospital or homebound programs. 
Twenty-six percent of respondents identified their principle teaching assignment as located in an urban setting, $41 \%$ as a suburban setting, and $33 \%$ as a rural setting.

\section{Instrumentation}

The survey mailed to potential respondents was developed using Agran, Snow, and Swaner's (1999) survey, which was expanded based on the functional model of self-determination described previously. The survey consisted of two sections. The first gathered demographic data summarized in the previous section of this article. The second was entitled "Teaching SelfDetermination" and consisted of 10 questions, several of which were in multiple parts. The first question in this section asked if respondents were familiar with the term self-determination ("yes" or "no"). If respondents indicated "yes," they were asked how the term was defined and to indicate all sources through which they were familiar with the term from the following options: undergraduate training, graduate training, district inservice, conferences or workshops, an educational text, professional journal articles, or from colleagues. The next question asked teachers to rate the importance to their students of seven instructional domains related to self-determination. Ratings could range from 1 to 6 , with 1 representing "low importance" and 6 representing "high importance." The instructional domains listed were drawn from the component elements described earlier, and consisted of (a) choice making, (b) decision making, (c) problem solving, (d) goal setting and attainment, (e) selfadvocacy, (f) self-management and self-regulation skills, and (g) self-awareness and self-knowledge. Each domain was defined with a one-sentence description. The next two questions asked respondents to rate how much promoting self-determination would help prepare their students for school and for postschool life. Responses ranged from 1 ("not helpful") to 6 ("very helpful"). Next, respondents were asked to identify how many of their students have self-determination-related goals on their IEP or transition plans (i.e., "none," "some," or "all").

Teachers were then asked to identify ("yes" or "no") if they were currently teaching or had ever taught any of the following seven self-management strategies: self-monitoring, selfevaluation, self-reinforcement, self-instruction, goal setting or contracting, self-scheduling, or antecedent cue regulation. As before, each strategy was defined with a one-sentence example. The next-to-last question asked respondents to identify barriers that might lead them not to provide instruction to promote selfdetermination or not to teach student-directed learning strategies. Respondents were asked to select all viable reasons they might not do so from the options listed in Table 6. The final question asked teachers to identify ("yes" or "no") if they had implemented other strategies that might promote selfdetermination. Listed strategies included (a) student involvement in educational planning meetings, (b) structuring classroom environments to promote student-directed learning, (c) instructional activities in non-school settings, and (d) mentoring programs. (A copy of the survey can be obtained from the first author.)

\section{Analyses}

Overall trends and responses were represented in graphic and tabular formats. Mean scores were calculated for questions with Likert scale responses. We conducted separate analyses of variance on questions with Likert scale scores by primary environment (per IDEA definitions) or level of students' intellectual disability. To determine the latter, we compared responses of teachers who worked exclusively with students with mild cognitive disabilities (learning disability and/or mild mental retardation, $n=297$ ) or severe cognitive disabilities (moderate or severe mental retardation, $n=365$ ). No other disability category had a sufficient number of respondents who indicated they worked exclusively with that population to include in the comparison. For the former, we compared only the four most frequently reported environments (i.e., regular class, resource room, self-contained class, separate school). Finally, we conducted chi-square analyses on four questions to which respondents indicated a "yes" or "no" response by learning environment and level of cognitive disability.

\section{Results}

For all respondents, $60 \%(n=725)$ indicated they were familiar with the self-determination construct. The sources through which they were familiar with the term are depicted in Table 3. The source most frequently cited was articles in professional journals $(n=433)$, followed by a conference or workshop $(n=$ $358)$, or graduate training $(n=315)$. Table 4 provides the mean scores and frequency for responses to ratings of the relative importance to students of each instructional domain. These data reveal that all domains were rated

TABLE 3. Source of Information About Self-Determination

\begin{tabular}{lcc}
\hline \multicolumn{1}{c}{ Source } & $\begin{array}{c}\text { Frequency } \\
\text { responding } \\
\text { "yes" }\end{array}$ & $\begin{array}{r}\text { \% of total } \\
\text { respondents } \\
(\mathrm{n}=1,219)\end{array}$ \\
\hline Professional journal articles & 433 & 36 \\
Conference or workshop & 358 & 30 \\
Graduate training & 315 & 26 \\
Education textbook & 163 & 13 \\
Undergraduate training & 144 & 12 \\
Colleagues & 170 & 14 \\
District inservice training & 114 & 9 \\
\hline
\end{tabular}

Note. Respondents could select multiple responses. 
TABLE 4. Percentage of Respondents Ranking Instruction in Self-Determination as Not, Moderately, or Very Important, and Mean Scores and Standard Deviations for Each Domain

\begin{tabular}{lcccc}
\hline & \multicolumn{3}{c}{ \% ranking } & \\
\cline { 2 - 4 } Instructional domain & $\begin{array}{c}\text { 1or2 } \\
\text { Not } \\
\text { important }\end{array}$ & $\begin{array}{c}\text { 3or4 } \\
\text { Moderately } \\
\text { important }\end{array}$ & $\begin{array}{c}\text { 5or6 } \\
\text { Very } \\
\text { important }\end{array}$ & Mean (SD) \\
\hline Decisionmaking & 5.2 & 21.2 & 73.6 & $4.93(1.22)$ \\
Problem solving & 6.0 & 20.4 & 73.6 & $4.94(1.23)$ \\
Choicemaking & 2.2 & 24.6 & 73.2 & $5.03(1.05)$ \\
Self-management & 7.2 & 27.0 & 65.8 & $4.77(1.29)$ \\
Self-awareness & 6.0 & 29.7 & 64.4 & $4.77(1.22$ \\
Self-advocacy & 8.9 & 31.8 & 59.3 & $4.56(1.34)$ \\
Goal setting & 10.4 & 33.6 & 56.0 & $4.46(1.38)$ \\
\hline
\end{tabular}

as moderately or very important. Specifically, decision making, problem solving, and choice making received the highest mean rankings. The mean score for the question asking teachers to what extent promoting self-determination would help prepare students for success in school was 4.84 (out of 6 possible), while the mean score for the identical question focusing on success for postschool life was 5.27. Thirty-one percent of respondents indicated that none of their students had self-determination-related goals on their IEP or transition plan, $47 \%$ indicated some students did, and $22 \%$ indicated that all their students had self-determination-related goals.

Table 5 provides the frequency of respondents who indicated they had previously taught or were currently teaching self-directed learning strategies. The most frequently identified strategy taught was self-reinforcement $(n=894)$, followed by self-evaluation $(n=883)$, and goal setting $(n=793)$. The reasons why teachers might not provide instruction to promote selfdetermination or teach self-management strategies are listed in Table 6. The most frequently identified reason teachers did not or would not teach student-directed learning strategies or promote self-determination was that they did not believe their students would benefit from such instruction $(n=517)$. The second most frequent reason cited was that teachers did not believe they had sufficient information or training to do so $(n=501)$. Finally, 851 teachers indicated they involved students in educational planning meetings, 683 structured the classroom environment to promote student-directed learning, 579 provided instructional activities in non-school settings, and 280 implemented mentoring programs.

Analysis of variance comparing ratings of teachers who taught exclusively students with mild cognitive disabilities or exclusively severe cognitive disabilities on the importance of teaching the various self-determination-related instructional domain areas yielded significant differences across all seven domains: choice making, $F(1,660)=4.15, \mathrm{p}<.042$; decision
TABLE 5. Frequency of Respondents Who Had Taught or Are Teaching Student-Directed Learning Strategies

\begin{tabular}{lcc}
\hline $\begin{array}{c}\text { Student-directed } \\
\text { learning } \\
\text { strategy }\end{array}$ & $\begin{array}{c}\text { Frequency } \\
\text { responding } \\
\text { "yes" }\end{array}$ & $\begin{array}{c}\% \text { of total } \\
\text { respondents } \\
(\mathrm{n}=1,219)\end{array}$ \\
\hline Self-monitoring & 633 & 52 \\
Self-evaluation & 883 & 72 \\
Self-reinforcement & 894 & 73 \\
Self-instruction & 556 & 46 \\
Goal setting or behavioral & 793 & 65 \\
$\quad$ contracting & 430 & 35 \\
Self-scheduling & 618 & 51 \\
Antecedent cue regulation & & \\
\hline
\end{tabular}

making, $F(1,661)=5.47, \mathrm{p}<.02$; problem solving, $F(1,657)=$ 10.67 , p < .001; goal setting, $F(1,659)=23.32$, p <.0001; selfadvocacy, $F(1,660)=12.02, \mathrm{p}<.001$; self-management, $F(1$, $655)=4.49, \mathrm{p}<.034$; self-awareness, $F(1,661)=7.98, \mathrm{p}<.005$. In all domain areas except choice making, teachers of students with mild disabilities rated instructional efforts as more important to their students than did teachers of students with severe disabilities. Mean scores for both groups are graphed in Figure 1. There were also significant differences on mean scores for the importance of such instruction to success in school: mild $=5.12$, $S D=.82 ;$ severe $=4.41, S D=1.32 ; F(1,636)=16.08, \mathrm{p}<.0001$; and in postschool life: mild $=5.47, S D=.74$; severe $=4.88, S D=$ $1.31 ; F(1,636)=6.81, \mathrm{p}<.009$, where higher scores reflected higher importance. A one-way analysis of variance for differences on responses to the seven domains from all respondents with educational setting as the independent variable was conducted. There were significant differences by environment for all questions: 
TABLE 6. Frequency of Respondents and Percentage of Total Respondents Identifying Barriers to Self-Determination

\begin{tabular}{lcc}
\hline $\begin{array}{c}\text { Reason for not providing instruction } \\
\text { in self-determination }\end{array}$ & $\begin{array}{c}\text { Frequency } \\
\text { "yes" }\end{array}$ & (n = 1,219) \\
\hline $\begin{array}{l}\text { Students would not benefit from instruction in these areas } \\
\text { Teacher does not have sufficient training/information on } \\
\quad \text { teaching this area }\end{array}$ & 517 & 42 \\
Teacher does not have authority to provide instruction & 501 & 41 \\
$\quad$ in those ares & 389 & 32 \\
Students need instruction in other areas more urgently & 351 & 29 \\
Teacher not aware of curricular/assessment materialsstrategies & 203 & 17 \\
Teacher does nothave sufficient time to provide & 184 & 15 \\
$\quad$ instruction in those areas & 148 & 12 \\
Students already have adequate self-determination skills & 52 & 4 \\
Someone else responsible for instruction in those areas & & \\
\hline
\end{tabular}

choice making, $F(3,1153)=8.83, \mathrm{p}<.0001 ;$ decision making, $F(3,1157)=10.58, p<.0001$; problem solving, $F(3,1152)=11$. $16, p<.0001$; goal setting, $F(3,1155)=17.58, p<.0001$; selfadvocacy, $F(3,1155)=7.40, p<.0001$; self-management, $F(3$, $1151)=4.86, p<.002$; self-awareness, $F(3,1158)=5.82, p<.001$. Means for instructional domain by learning environment are provided in Figure 2, and significance levels resulting from the post hoc multiple-comparisons analyses (Scheffe) are presented in Table 7.

There were no differences between teachers who taught students with mild versus severe cognitive disabilities on chisquare analyses of their knowledge about the term selfdetermination (see Table 8) but significant differences on teacherreported use of student-directed learning strategies based on level of cognitive ability. Table 9 presents these data.

\section{Discussion}

Findings suggested that, nationally, teachers working with secondary-age students are generally familiar with the selfdetermination construct. First, $60 \%$ of respondents indicated their familiarity with the term. The most frequently cited exposure to the construct was via journal articles, conference presentations, and graduate training. Second, teachers rated instruction in the component elements of self-determination (e.g., choice making, goal setting) as important, with between $90 \%$ and $98 \%$ of respondents indicating that a given instructional domain was either "moderately important" or "very important" for their students. Third, teachers indicated they believed that promoting self-determination would be "very helpful" to prepare their students for success in postschool life and "somewhat helpful" to ensure their success in school. Fourth, teachers' self-reported implementation of student-directed learning strategies was promising, with the percentage of teachers who indicated they taught students self-management strategies ranging from 35 (self-scheduling) to more than 70 (self-evaluation, self- instruction, goal setting or behavioral contracting).

These findings are promising. They also mirror Agran and colleagues' (1999) results showing that teachers think selfdetermination is an important instructional area. Nevertheless, results from questions examining the degree to which teachers moved beyond stating their belief in the importance of promoting self-determination to implementing strategies to do so were mixed. Despite the fact that a high percentage of respondents indicated that instruction in component elements of self-determination was very important, only $22 \%$ indicated that all their students had IEP goals in this area. Thirty-one percent indicated that none of their students had such goals. In addition, one third of respondents reported they did not involve students in educational planning at all. Given our previous findings when actually examining IEP transition goals (Wehmeyer \& Schwartz, 1998), it seems evident that teachers' perceptions of the importance of self-determination may not be translating to instructional activities to promote selfdetermination.

A variety of reasons may explain why teachers may not provide instruction to promote self-determination. The most frequently cited was that their students would not benefit from instruction in these areas. Analysis examining differences in responses to this question between teachers working exclusively with students with mild cognitive disabilities or exclusively with students with severe cognitive disabilities (see Table 9) indicated that significantly more teachers of students with severe disabilities responded "yes" to the "no benefit" option $(n=198)$ than expected $(n=124)$; fewer teachers of students with mild disabilities said "yes" $(n=28)$ than expected $(n=102)$. In addition, teachers who worked with students with more severe disabilities rated instruction in the self-determination domain areas as less important than did teachers of students with mild disabilities across all domain areas except choice making.

These findings are not surprising considering that people with severe intellectual disabilities may be less likely to learn 


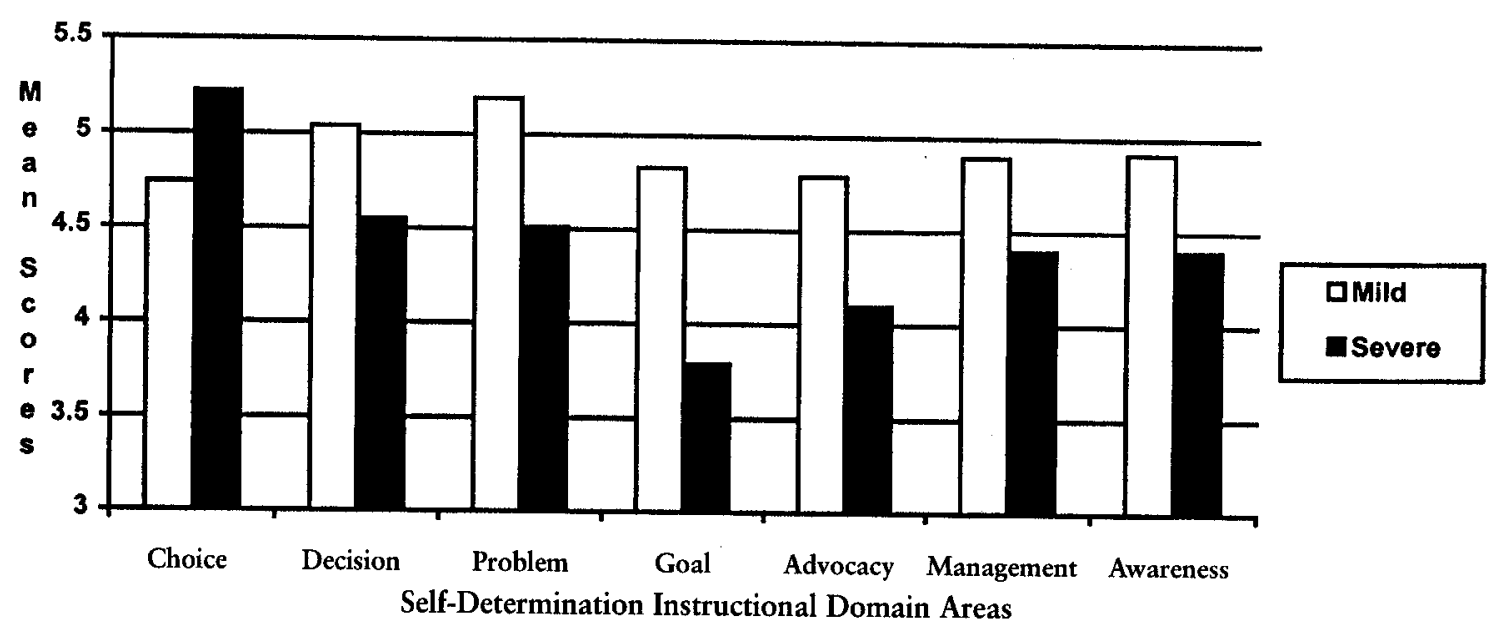

FIGURE 1. Differences between mean scores of teachers working with students with mild cognitive or severe cognitive disabilities on importance of teaching self-determination domain areas.

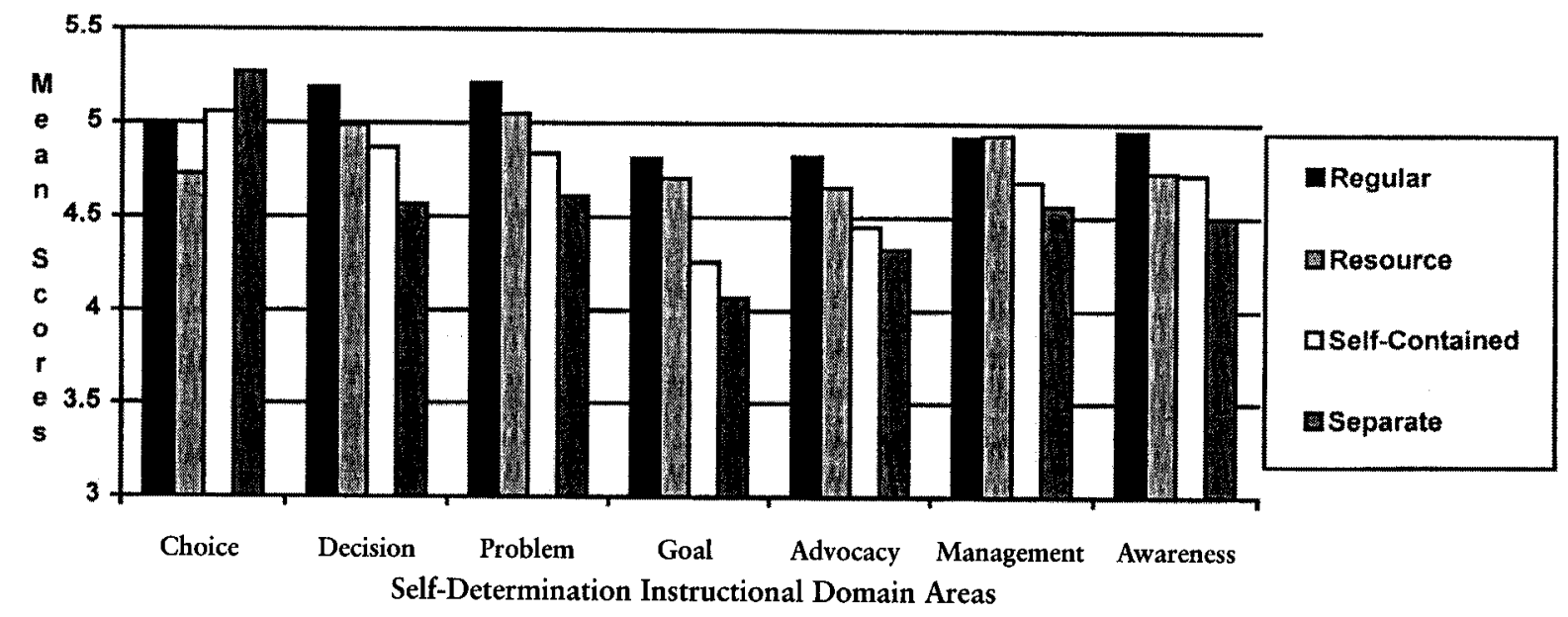

FIGURE 2. Differences between mean scores of teachers working with students who receive educational services in one of four environments on importance of teaching self-determination domain areas.

complex skills like decision making or problem solving. Also, since the professional literature in severe disabilities has focused largely, if not exclusively, on the importance of supporting choice making for this population (Wehmeyer, 1998), other component elements have received limited attention.

We are, however, concerned that the severity of disability appeared to influence teachers' perceptions of the relative benefit of instruction in self-determination. Self-determination is, fundamentally, about exerting control over one's life and one's destiny. People who are self-determined are causal agents in their lives in that they make things happen to and for them (Wehmeyer et al., 1998). The perception that students with severe disabilities cannot benefit from instruction may be tied to an interpretation of self-determination that places undue emphasis on performing behaviors independently, without appropriate supports (Wehmeyer, 1998). Although it is undoubtedly true that the severity of one's cognitive disability impacts the number and complexity of skills one can acquire and that some individuals with severe disabilities will not be able to make independent decisions or solve complex problems, this does not mitigate the importance of providing instructional experiences to enable these students to become more self-determined.

Multiple studies in the education and psychology literature (e.g., Agran et al., 1986; Frea \& Hughes, 1997; Hughes, 1992) show that individuals with severe disabilities can learn to self-regulate and self-manage their own behavior, become less dependent on others, and express preferences and use 
TABLE 7. Significance Levels From Post Hoc Multiple Comparisons

\begin{tabular}{|c|c|c|c|}
\hline Classroom setting & Regular & $\begin{array}{l}\text { uctional don } \\
\text { Resource }\end{array}$ & Self-contained \\
\hline \multicolumn{4}{|l|}{ Choice making } \\
\hline Regular & - & & - \\
\hline Resource & .062 & - & - \\
\hline Self-contained & .797 & .003 & - \\
\hline Separate campus & .041 & .000 & .165 \\
\hline \multicolumn{4}{|l|}{ Decision making } \\
\hline Regular & - & - & - \\
\hline Resource & .350 & & \\
\hline Self-contained & .004 & .707 & - \\
\hline Separate campus & .000 & .010 & .045 \\
\hline \multicolumn{4}{|l|}{ Problem solving } \\
\hline Regular & - & - & - \\
\hline Resource & .563 & - & - \\
\hline Self-contained & .000 & .224 & - \\
\hline Separate campus & .000 & .007 & .206 \\
\hline \multicolumn{4}{|l|}{ Goal setting } \\
\hline Regular & - & & \\
\hline Resource & .867 & - & - \\
\hline Self-contained & .000 & .002 & - \\
\hline Separate campus & .000 & .000 & .467 \\
\hline \multicolumn{4}{|l|}{ Self-advocacy } \\
\hline Regular & - & & - \\
\hline Resource & .573 & & - \\
\hline Self-contained & .001 & .322 & - \\
\hline Separate campus & .001 & .139 & .811 \\
\hline \multicolumn{4}{|l|}{ Self-management } \\
\hline Regular & - & - & - \\
\hline Resource & .675 & - & - \\
\hline Self-contained & .089 & .157 & - \\
\hline Separate campus & .028 & .047 & .729 \\
\hline \multicolumn{4}{|l|}{ Self-awareness } \\
\hline Regular & & & - \\
\hline Resource & .255 & - & - \\
\hline Self-contained & .075 & .675 & - \\
\hline Separate campus & .001 & .281 & .172 \\
\hline
\end{tabular}

those preferences to make choices (Wehmeyer et al., 1998). The fact that someone may not become completely independent in his or her decision-making capacity does not mean that he or she cannot become less dependent or more involved in decisions that impact his or her life. The fact that someone may not be able to independently solve complex problems does not mean that he or she might not become better able to participate in one or more steps in the problem-solving process. Being selfdetermined does not require that individuals do everything for themselves. People with severe physical disabilities can hire a personal care attendant to perform activities of daily living for them. Yet, if those activities are done under the control of or based on the preferences of the person with the disability, the fact that the person is not physically making his or her bed or folding laundry does not diminish his or her self-determination. Likewise, people with the most severe cognitive disabilities can learn to self-manage aspects of their lives; can and do express preferences that can contribute to making choices and decisions; and can, through instruction, opportunities, and adequate supports, become more self-determined.

We believe it is equally important to focus on instruction in these areas for students with severe disabilities, even if these students may not become independent in all or any of the areas. This was apparently not the belief of many respondents: Significantly more teachers of students with severe disabilities responded "yes" to the "students need instruction in other areas more urgently" question than expected. However, fewer teachers of students with mild disabilities said "yes" than expected. 
TABLE 8. Results of Chi-Square Analysis for Use of Student-Directed Learning Strategy by Level of Disability of Students Taught

\begin{tabular}{lccccc}
\hline \multirow{2}{*}{$\begin{array}{c}\text { Student-directed } \\
\text { learning strategy }\end{array}$} & $\begin{array}{c}\text { Yes } \\
\text { Expected }\end{array}$ & $\begin{array}{c}\text { Yes } \\
\text { Actual }\end{array}$ & $\begin{array}{c}\text { Yes } \\
\text { Expected }\end{array}$ & $\begin{array}{c}\text { Yes } \\
\text { Actual }\end{array}$ & pevere $^{\mathbf{2}}$ \\
\hline Self-monitoring & 133 & 155 & 163 & 141 & $.000 / 12.12$ \\
Self-evaluation & 201 & 218 & 244 & 228 & $.003 / 7.90$ \\
Self-reinforcement & 210 & 196 & 261 & 275 & $.010 / 5.91$ \\
Self-instruction & 126 & 145 & 154 & 136 & $.002 / 9.00$ \\
Goal setting & 181 & 227 & 217 & 171 & $.000 / 55.26$ \\
Self-scheduling & 92 & 92 & 116 & 116 & $.509 / .004$ \\
Antecedentcue regulation & 144 & 66 & 181 & 259 & $.000 / 151.7$
\end{tabular}

TABLE 9. Results of Chi-Square Analysis for Reasons for Not Teaching Self-Determination by Level of Disability of Students Taught

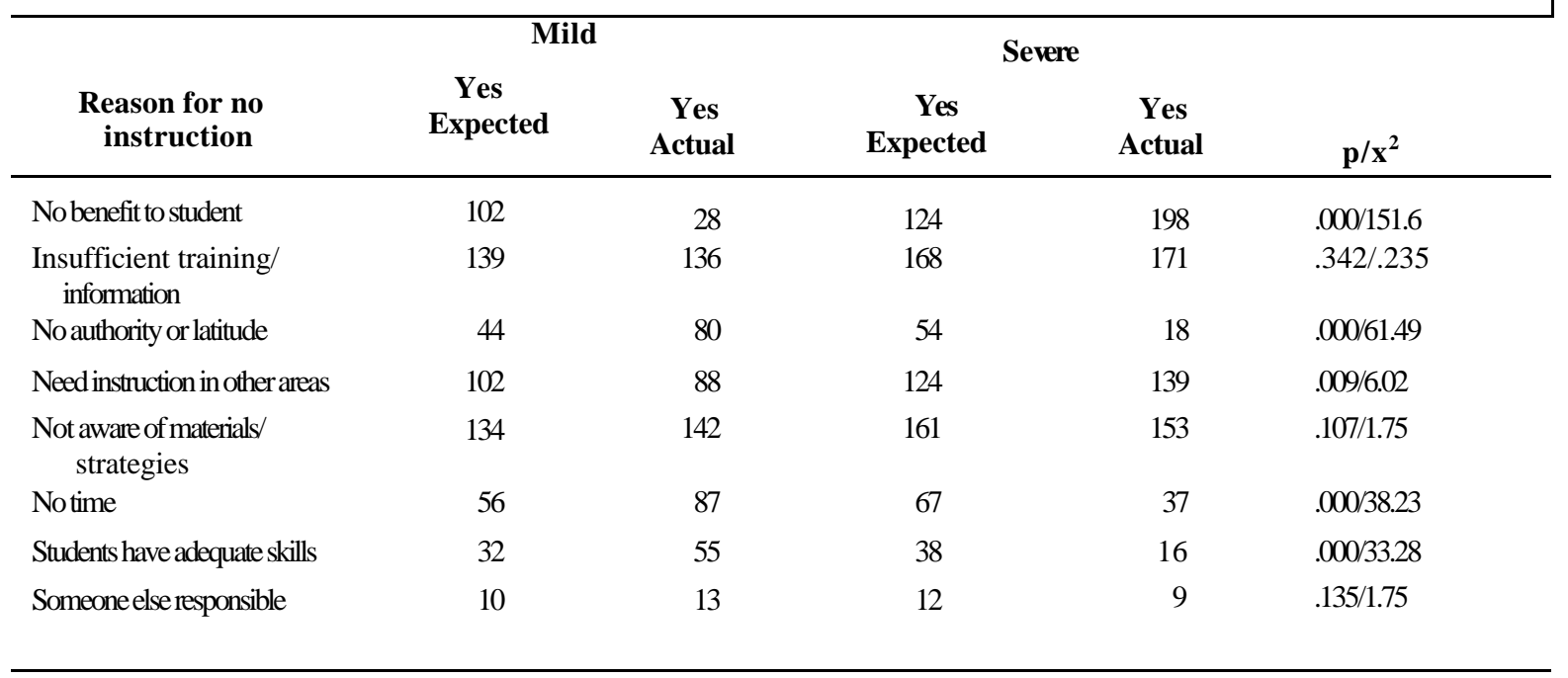

Additionally, teachers of students with mild disabilities were significantly and disproportionately more likely to use selfmonitoring, self-evaluation, self-instruction, and goal-setting strategies than were teachers of students with severe disabilities. Teachers in both groups were equally likely to use self-scheduling, which was the least frequently taught strategy for all respondents. In contrast, teachers of students with severe disabilities were more likely to use self-reinforcement and antecedent cue regulation. Again, we believe that it may be beneficial for teachers working with students with severe disabilities to teach students to self-monitor, self-evaluate, selfinstruct, and set and track goals, even if these students cannot do so completely independently. There are ample demonstrations in the literature indicating that students with severe disabilities can, for example, learn to self-instruct (Agran, Fodor-Davis, Moore, \& Deer, 1989; Hughes, 1992; Hughes, Killian, \& Fischer, 1996), as well as make choices (Hughes, Pitkin, \& Lorden, 1998).
With respect to the impact of the classroom setting in which students received their education, findings indicated that teachers working in less restrictive environments were also more likely to believe that teaching self-determination to students with disabilities was important. Unfortunately we cannot draw clear conclusions because it is likely that classroom setting was confounded with level of disability. However, students with severe disabilities are more likely to be served in separate classroom or separate campus settings, despite the fact that restrictive environments have been found to negatively impact the selfdetermination (Abery \& Stancliffe, 1996; Stancliffe \& Wehmeyer, 1995; Tosseboro, 1995; Wehmeyer \& Bolding, 1999) and quality of life (Wehmeyer \& Schwartz, 1998) of adults with mental retardation. Consequently, it is critical to examine educational environments to determine the degree to which they promote or restrict opportunities for students to (a) learn skills important to the emergence of self-determination, (b) practice those skills, and 
(c) develop perceptions that lead individuals to assume more control over their lives.

Several limitations to this study warrant consideration. Primarily, it is not possible to generalize the findings of the study to the population of all special educators for two reasons. First, we could not determine the survey response rate because we mailed it to a broad sample of educators but asked only a segment of that sample to return the survey (i.e., only teachers currently providing direct services to students). As described in the method section, the sample was constituted by purchasing the mailing list from two professional organizations, TASH and the Council for Exceptional Children (CEC). With the CEC list, we specified educators who belonged to either the Learning Disabilities division or the Mental Retardation and Developmental Disabilities division. By examining the percentage of teachers working with students with learning disabilities, mental retardation, and multiple disabilities over 14 years of age, we could provide a "best guess" estimate of the total number of survey recipients who might have fit the selection criteria (currently teaching students 14 and over). According to the 20th Annual Report to Congress on the Implementation of IDEA, approximately $39 \%$ of all teachers who teach students within these categories (learning disability, mental retardation, multiple disability) work with students ages 14 and over. Applying that to the total mailing for our study creates an estimate of a potential sample of 3,807 among the original 9,762 recipients. We received 1,219 surveys, or about one third of the 3,807 estimate. Obviously, this "best guess" assumes all of the original respondents were currently working directly with students, an unlikely assumption. Thus, we suggest that a worstcase estimate of the return rate is $33 \%$. In any case, this is somewhat low; so, readers should interpret findings cautiously.

A second reason to be cautious about generalizing these findings is that the sample was drawn from members of national advocacy and professional organizations. Findings, therefore, may represent a best-possible scenario because teachers who are members of organizations such as TASH and CEC are more likely to be familiar with the self-determination construct.

With these cautions in mind, it is possible to tentatively pose some recommendations for practice. First, a frequently identified barrier to providing instruction in selfdetermination was that teachers did not have sufficient training or information on promoting this outcome. While a growing number of resources are now available to teachers (see Field et al., 1998; Wehmeyer et al., 1998), there is still a need to move from pronouncements of the importance of self-determination to specific methods, materials, and instructional strategies that can enhance self-determination.

Second, it is evident that teachers need to learn strategies, through preservice and inservice education, to teach students to self-regulate and self-manage their learning. This seems particularly true for teachers of students with severe disabilities. Generally, it appears that teachers' knowledge of self-determination is superficial and there is a continued need to both disseminate information about existing methods, materials, and strategies that enable teachers to promote this outcome and to develop new strategies. Teachers seem to concur that this is important but seem less certain about how to promote selfdetermination.

Third, among our sample, the third most frequently cited barrier to teaching self-determination was a lack of authority to provide instruction in that area. This speaks to the need to consider self-determination within the school reform debate (Sands \& Wehmeyer, 1996). In discussing school reform issues, Sarason (1990) identified the need to address the power structures within school systems, including issues of teacher control and power. If we are to empower students to assume more control over their lives, it is necessary that we, in turn, empower teachers to have more authority and latitude to influence programmatic issues (Field et al., 1998). Administrators need to work to ensure that teachers have the latitude to infuse learning opportunities in areas such as problem solving, goal setting, and decision making into classroom instruction whether the content is math or functional life skills. Viewing self-determination as a stand-alone topic to be taught in a single class or as the responsibility of the transition teacher is insufficient. There is also the need to ensure that selfdetermination-related goals and objectives are incorporated into students' IEPs and transition plans. Finally, despite IDEA's mandate that students be involved in transition planning, fully one third of respondents did not seem to involve students in educational planning and decision making. Teachers and school districts need to go beyond simply inviting students to meetings and, instead, they need to adequately prepare students to become active, equal partners in the education and transition planning and decisionmaking process (Wehmeyer \& Sands, 1998).

\section{RFFERENCES}

Abery, B., \& Stancliffe, R. (1996). The ecology of self-determination. In D. J. Sands \& M. L. Wehmeyer (Eds.), Self-determination across the life span: Independence and choice for people with disabilities (pp. 111145 ). Baltimore: Brookes.

Agran, M. (1997). Student-directed learning: Teaching self-determination skills. Pacific Grove, CA: Brooks/Cole.

Agran, M., Fodor-Davis, J., \& Moore, S. C. (1986). The effects of selfinstructional training on job-task sequencing: Suggesting a problemsolving strategy. Education and Training in Mental Retardation, 21, 273-281.

Agran, M., Fodor-Davis, M., Moore, S., \& Deer, M. (1989). The application of a self-management program on instruction-following skills. Journal of the Association for Persons with Severe Disabilities, 14, 147-154.

Agran, M., Snow, K., \& Swaner, J. (1999). Teacher perceptions of selfdetermination: Benefits, characteristics, strategies. Education and Training in Mental Retardation and Developmental Disabilities, 34, 293-301.

Brownell, K. D., Colletti, G., Ersner-Hershfield, R., Hershfield, S. M., \& Wilson, G. T. (1977). Self-control in school children: Stringency and leniency in selfdetermined and externally imposed performance standards. Behavior Therapy, 8, 442-455.

Field, S., \& Hoffman, A. (1996). Steps to self-determination: A curriculum to help adolescents learn to achieve their goals. Austin, TX: PRO-ED. 
Field, S., Hoffman, A., \& Spezia, S. (1998). Self-determination strategies for adolescents in transition. Austin, TX: PRO-ED.

Field, S., Martin, J., Miller, R., Ward, M., \& Wehmeyer, M. (1998a). A practical guide to teaching self-determination. Reston, VA: Council for Exceptiona Children.

Field, S., Martin, J., Miller, R., Ward, M., \& Wehmeyer, M. (1998b). Selfdetermination for persons with disabilities: A position statement of the Division on Career Development and Transition. Career Development for Exceptional Individuals, 21, 113-128.

Frea, W. D., \& Hughes, C. (1997). Functional analysis and treatment of social communicative behavior of adolescents with developmental disabilities. Journal of Applied Behavior Analysis, 30, 701-704.

Graham, S., \& Harris, K. R. (1989). Improving learning disabled students' skills at composing essays: Self-instructional strategy training. Exceptional Children, 56, 214-23 1

Halloran, W. D. (1993). Transition services requirement: Issues, implications, challenge. In R. C. Eaves \& P. J. McLaughlin(Eds.), Recent advances in special education and rehabilitation (pp. 210-224). Boston: Andover.

Halpern, A. S., Herr, C. M., Wolf, N. K., Doren, B., Johnson, M. D., \& Lawson, J. D. (1997). Next S.T E.P.: Student transition and educational planning. Austin, TX: PRO-ED.

Hughes, C. (1992). Teaching self-instruction utilizing multiple exemplars to produce generalized problem-solving by individuals with severe mental retardation. American Journal on Mental Retardation, 97, 302-314.

Hughes, C., \& Agran, M. (1994). Teaching persons with severe disabilities to use self-instruction in community settings. Journal of the Association for Persons with Severe Handicaps, 18, 261-274.

Hughes, C., Harmer, M. L., Killian, D. J., \& Niarhos, F. (1995). The effects of multiple-exemplar self-instructional training on high school students' generalized conversational interactions. Journal of Applied Behavior Analysis, 28, 201-218.

Hughes, C., Hugo, K., \& Blatt, J. (1996). A self-instructional model for teaching generalized problem solving within a functional task sequence. American Journal on Mental Retardation, 100, 565-579.

Hughes, C., Killian, D. J., \& Fischer, G. M. (1996). Validation and assessment of a conversational interaction intervention. American Journal on Mental Retardation, 100, 493-509.

Hughes, C., Kim, J., Hwang, B., Killian, D. J., Fischer, G. M., Brock, M. L., Godshall, J. C., \& Houser, B. (1997). Practitioner-validated econdary transition support strategies. Education and Training in Mental Retardation and Developmental Disabilities, 32, 201-212.

Hughes, C., Pitkin, S. E., \& Lorden, S. W. (1998). Assessing preferences andchoices of persons with severe and profound mental retardation. Education and Training in Mental Retardation and Developmental Disabilities, 33, 299-316.

Hughes, C., \& Rusch, F. R. (1989). Teaching supported employees with severe mental retardation to solve problems. Journal of Applied Behavior Analysis, 22, 365-372.

Kapadia, S., \& Fantuzzo, J. W. (1988). Training children with developmental disabilities and severe behavior problems to use self-management procedures to sustain attention to preacademic/academic tasks. Education and Training in Mental Retardation, 23, 59-69.

Malone, L. D., \& Mastropieri, M. A. (1992). Reading comprehension instruction: Summarization and self-monitoring training for students with learning disabilities. Exceptional Children, 58, 270-279.

Martella, R. C., Leonard, I. J., Marchand-Martella, N. E., \& Agran, M. (1993). Selfmonitoring negative statements. Journal of Behavioral Education, 3, 77 86

Martin, J. E., Marshall, L. H., Maxson, L., \& Jerman, P. (1996). Self-directed IEP: Teacher's manual. Longmont, CO: Sopris West.

McCarl, J. J., Svobodny, L., \& Beare, P. L. (1991). Self-recording in a classroom for students with mild to moderate mental handicaps: Effects on productivity and on-task behavior. Education and Training in Mental Retardation, 26, 79-88.

Rusch, F. R., McKee, M., Chadsey-Rusch, J., \& Renzaglia, A. (1988). Teaching a student with severe handicaps to self-instruct: A brief report. Education and Training in Mental Retardation, 23, 51-58.
Salend, S. J., Ellis, L. L., \& Reynolds, C. J. (1989). Using self-instruction to teach vocational skills to individuals who are severely retarded. Education and Training in Mental Retardation, 24, 248-254.

Sands, D. J., \& Wehmeyer, M. L. (1996). Future directions in self-determination: Articulating values and policies, reorganizing organizational structures, and implementing instructional practices. In D. J. Sands \& M. L. Wehmeyer (Eds.), Self-determination across the life span: Independence and choice for people with disabilities (pp. 331-344). Baltimore: Brookes.

Schunk, D. H. (1981). Modeling and attributional effects on children's achievement: A self-efficacy analysis. Journal of Educational Psychology, 73, 93-105.

Stancliffe, R., \& Wehmeyer, M. L. (1995). Variability in the availability of choice to adults with mental retardation. Journal of Vocational Rehabilitation, 5 , 319-328.

Szymanski, E. M. (1994). Transition: Life-span and life-space considerations for empowerment. Exceptional Children, 60, 402-410.

Tossebro, J. (1995). Impact of size revisited: Relation of number of residents to selfdetermination and deprivatization. American Journal on Mental Retardation, 100, 59-67.

Trammel, D. L., Schloss, P. J., \& Alper, S. (1994). Using self-recording, evaluation and graphing to increase completion of homework assignments. Jou rnal of Learning Disabilities, 27, 75-81.

VanReusen, A. K., Bos, C. S., Schumaker, J. B., \& Deshler, D. D. (1994). The self-advocacy strategy for education and transition planning. Lawrence, KS: Edge Enterprises.

Wehman, P. (1993). Transition from school to adulthood for young people with disabilities: Critical issues and policies. In R. C. Eaves \& P. J. McLaughlin (Eds.), Recent advances in special education and rehabilitation ( $p p$. 178-192). Boston: Andover.

Wehmeyer, M. L. (1996). Self-determination as an educational outcome: How does it relate to the educational needs of our children and youth? InD.J.Sands\& M. L. Wehmeyer (Eds.), Self-determination across the life span: Independence and choice for people with disabilities ( $p$ p. 17 36). Baltimore: Brookes.

Wehmeyer, M. L. (1997). Self-determination as an educational outcome. A definitional framework and implications for intervention. Journal of Developmental and Physical Disabilities, 9, 175-209.

Wehmeyer, M. L. (1998). Self-determination and individuals with significant disabilities: Examining meanings and misinterpretations. Journal of the Association for Persons with Severe Handicaps, 23, 5-16.

Wehmeyer, M. L. (1999). A functional model of self-determination: Describing development and implementing instruction. Focus on Autism and Other Developmental Disabilities, 14, 53-61.

Wehmeyer, M. L., Agran, M., \& Hughes, C. (1998). Teaching self-determination to students with disabilities: Basic skills for successful transition. Baltimore: Brookes.

Wehmeyer, M. L., \& Bolding, N. (1999). Self-determination across living and working environments: A matched-sample study of adults with mental retardation. Mental Retardation, 37, 353-363.

Wehmeyer, M. L., Kelchner, K., \& Richards, S. (1996). Essential characteristics of self-determined behaviors of adults with mental retardation and developmental disabilities. American Journal on Mental Retardation, 1 00,632-642.

Wehmeyer, M. L., \& Sands, D. J. (1998). Making it happen: Student involvement in education planning, decision-making, and instruction. Baltimore: Brookes.

Wehmeyer, M. L., Sands, D. J., Doll, B., \& Palmer, S. (1997). The development of self-determination and implications for educational interventions with students with disabilities. International Journal of Disability, Development, and Education, 44, 305-328.

Wehmeyer, M. L., \& Schwartz, M. (1997). Self-determination and positive adult outcomes: A follow-up study of youth with mental retardation or learning disabilities. Exceptional Children, 63, 245-255.

Wehmeyer, M. L., \& Schwartz, M. (1998). The self-determination focus of transition goals for students with mental retardation. Career Development for Exceptional Individuals, 21, 75-86. 